\title{
A rare case presentation of an anomalous uterus mimicking ovarian tumour
}

\author{
M. Mohanambal, Wills G. Sheela*
}

Department of Obstetrics and Gynecology, SSSMCRI, Ammapettai, Kancheepuram, Tamil Nadu, India

Received: 17 March 2017

Accepted: 21 April 2017

\section{* Correspondence:}

Dr. Wills G. Sheela,

E-mail: drgwillssheelaa@yahoo.in

Copyright: (C) the author(s), publisher and licensee Medip Academy. This is an open-access article distributed under the terms of the Creative Commons Attribution Non-Commercial License, which permits unrestricted non-commercial use, distribution, and reproduction in any medium, provided the original work is properly cited.

\section{ABSTRACT}

Mullerian anomalies occur in 1:1000-3000 females. Uterus didelphys and obstructed hemangioma with a septum contribute to $10 \%$ anomalies. Young girls present with severe dysmenorrhea, hematometra, hematocolpos and recurrent pregnancy loss. A 16-year-old teenager presented like a torsion of complex ovarian tumour is presented here. Intra operative findings was uterus didelphys with well-developed 2 horns, tubes and ovaries. On left ovary, a hemorrhagic corpus luteal cyst of size $5.2 * 4 \mathrm{~cm}$ was seen with $50 \mathrm{ml}$ of hemoperitoneum. Diagnosis was confirmed histopathologically. This case is reported for the unusual presentation of an anomalous uterus mimicking torsion ovarian tumour.

Keywords: Complex ovarian tumour, Haemorrhagic corpus luteum cyst, Uterus didelphys

\section{INTRODUCTION}

Mullerian anomalies occur due to improper development of urogenital sinus and the external genital organs. Mullerian duct anomalies result from defective fusion, canalisation and absorption of median septum of female reproductive system.

Uterus didelphys occur when two mullerian ducts fail to fuse along the whole length, but developing normally with tubes and ovaries, two cervix and a septum in the vagina.

Ovaries develop simultaneously by $5^{\text {th }}$ week from the genital ridge and descending down from original lumbar position to pelvic brim, on either side of the uterus. Arrest in any of the developmental stages cause genital, renal and urinary tract anomalies. We report a rare case of uterus didelphys with haemorrhagic corpus luteum cyst which presented as torsion of complex ovarian tumour. ${ }^{1}$

\section{CASE REPORT}

A 16-year-old unmarried teenager presented with acute colicky abdominal pain with vomiting and fainting attack. She was referred by a sonologist with the diagnosis of complex adnexal mass $5 * 4.5 \mathrm{~cm}$ with double uterus. Patient was in shock, dehydrated and emaciated. She gave history of severe dysmennorhoea since menarche at the age of 13 years. Loss of appetite, loss of weight and distension of lower abdomen for 3 months was present.

A clinical diagnosis of torsion ovarian malignant tumour was made and laparotomy was done. To our surprise, the intraoperative finding was double uterus with welldeveloped horns, tubes and ovaries. On left ovary, there was a hemorrhagic corpus luteal cyst with $50 \mathrm{ml}$ of hemoperitoneum. The hemorrhagic cyst was removed, biopsy from opposite side of ovary was taken and sent for histopathology. Abdomen explored. There was no ascitis, omentum was normal and no palpable lymph nodes. Postoperative period was uneventful. Histopathological 
diagnosis confirmed hemorrhagic corpus luteal cyst. Per speculum examination showed two cervix and no vaginal septum.

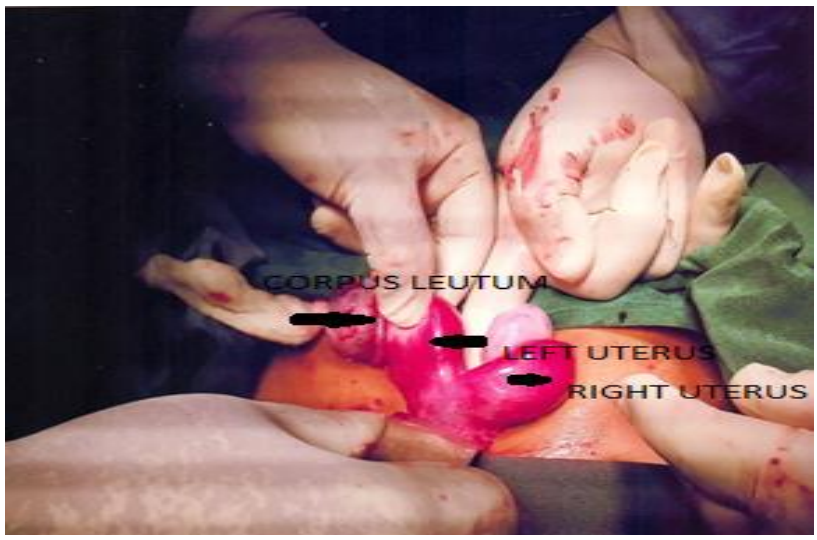

Figure 1: Uterus didelphys with right and left corpus.

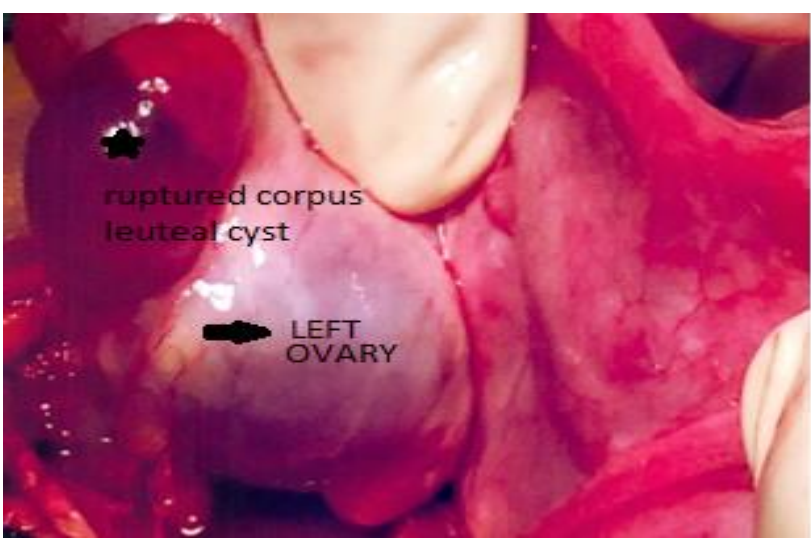

Figure 2: Ruptured corpus luteal cyst $4 \times 3$ cms.

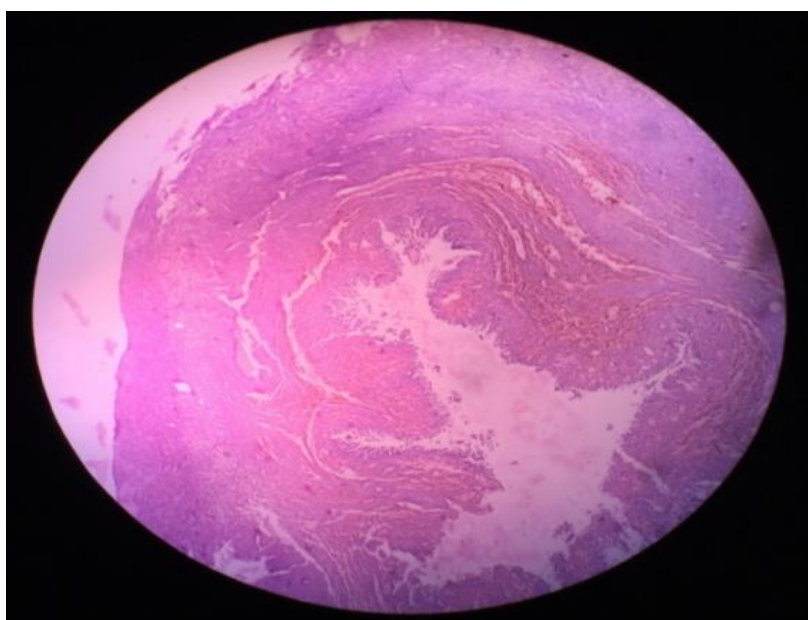

Figure 3: Haemorrhagic follicular cyst -HandE 4X shows ovarian tissue with cyst lined by luteinized granulosa and theca cells with haemorrhagic areas.

This study was conducted in the department of obstetrics and gynecology, King George's Medical University, Lucknow, Uttar Pradesh, India. The hospital is a tertiary institute with a 250-bedded department of obstetrics and gynecology. The protocol was approved by institution's ethics committee. It was a prospective observational study. All the women with preeclampsia from 30 weeks gestation onwards and willing to participate in the study were enrolled. A written informed consent was taken prior to enrolment. Women with known fetal congenital anomalies or diabetes mellitus were excluded from the study.

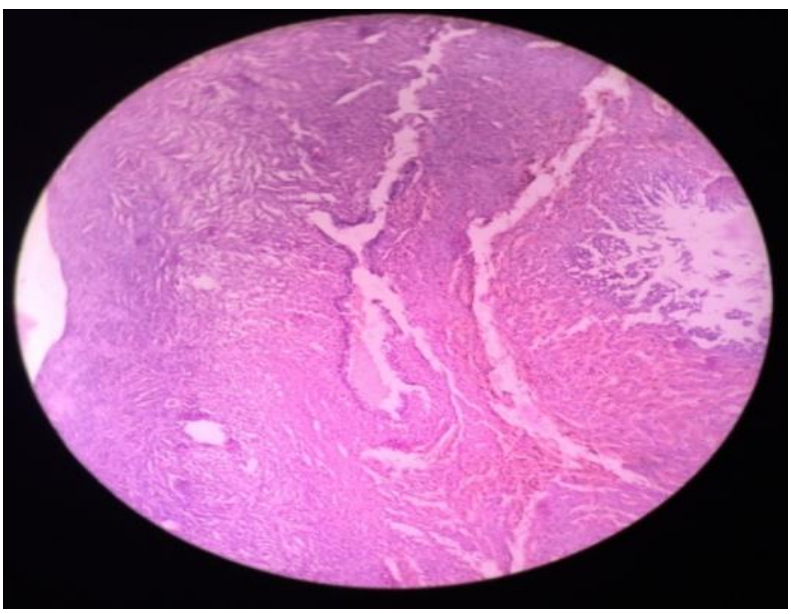

Figure 4: Haemorrhagic follicular cyst in high power microscope.



Figure 5: Cystic lining with ovarian tissue in $4 x$.

\section{DISCUSSION}

This case is reported for its rarity and unusual presentation of an anomalous uterus mimicking a torsion of malignant ovarian complex cyst in a 16-year-old unmarried teenager. She presented as a case of acute abdomen with loss of apetite, loss of weight and distension of lower abdomen for 3 months. She was referred by a sonologist as a case of double uterus with complex adnexal mass of size $5.4 * 4.5 \mathrm{~cm}$. In 1991 paediatric surgeon Dras $\mathrm{S}$ has reported uterus didelphys with obstructed hemivagina with haematometra in young girl who presented with acute abdominal pain. ${ }^{1}$ Ballbsic 
from Rome has reported a girl who presented with acute abdomen had uterus didelphys, double vagina and haematometra. $^{2}$ Klimek P from Switzerland has reported in a 13 year old post menarcheal girl presenting with acute abdominal pain had haematometra of right uterine horn in a uterus didelphys and imperforate right cervix. ${ }^{3}$ Bhattacharya from India has reported in a 46 year old lady who presented with irregular periods lower abdominalpain and a palpable firm mass of size $16 * 10$ $\mathrm{cm}$ had uterus didelphys and a fibroid on the anterior wall of left uterine horn and a cyst of size $3 * 2 \mathrm{~cm}$ on left ovary. ${ }^{4}$

Pervaginal exam revealed two cervices and incomplete vaginal septum. Nahar S from Bangladesh has reported in a 14-year-old girl, uterusdidelphys misleading as ovarian cyst. ${ }^{5}$ Left uterus was non-communicated with vagina forming a haematometra. Laffitte GS from Puerto Rico published in 2013 American journal has reported, a cystic adnexal mass in a 16-year-old girl with the clinical diagnosis of ovarian pathology turned out to be uterus didelphyswihhaematometra and haematosalphinx. ${ }^{6}$ Present case presented as an acute abdomen mimicking torsion ovarian tumour turned out as uterus didelphys with haemorrhagic corpus luteal cyst confirmed histologically for which we did not find any references.

\section{CONCLUSION}

Abdomen is a magic box which brings out surprises to the surgeon. This case was operated with the clinical diagnosis of torsion malignant ovarian tumour in a teenager (CA125 was within normal). All that glitters are not gold. We suspected malignancy of ovary which turned out to be benign condition postoperatively. Mullerian anomalies may mimic ectopic pregnancy, torsion of adnexal mass. High level suspicion in clinical diagnosis and adequate evaluation in support of the diagnosis is mandatory before deciding for surgical procedure since all reported cases are incidental finding when laprotomy was done in acute abdomen.
Funding: No funding sources Conflict of interest: None declared

Ethical approval: Not required

\section{REFERENCES}

1. Skondras KG, Moutsouris CC, Vaos GC, Barouchas GC, Demetriou LD. Uterus didelphys with an obstructed hemivagina and ipsilateral renal agenesis: a rare cause of acute abdomen in pubertal girls. J Pediatr Surg. 1991;26(10):1200-1.

2. Ballesio L, Andreoli C, De Cicco ML, Angeli ML, Manganaro L. Hematocolpos in double vagina associated with uterus didelphus: US and MR findings. Europ J Radiol. 2003;45(2):150-3.

3. Klimek P, Klimek M, Kessler U, Oesch V, Wolf R, Stranzinger E et al. Hematometra presenting as an acute abdomen in a 13-year-old postmenarchal girl: a case report. J Med Case Reports. 2012;6(1):419.

4. Bhattacharya K, Ramakrishnan R, Gopalan TR, Barua P, Vijayaraghavan J. Uterus didelphys with fibroid uterus and ovarian cyst--rare Muellerian malformation. J Indian Med Assoc. 2006;104(6):336-7.

5. Nahar S, Das B, Begum F. Didelphys uterus: misleading as ovarian cyst. Bangladesh Med J Khulna. 2013;45(1-2):30-2.

6. Santacana-Laffitte G, Ruiz L, Pedrogo Y, Colon E. Cystic adnexal mass in a 16-year-old female: Ovarian pathology or complication of a Müllerian anomaly? Am J Case Reports. 2013;14:153-6.

Cite this article as: Mohanambal M, Sheela WG. A rare case presentation of an anomalous uterus mimicking ovarian tumour. Int J Reprod Contracept Obstet Gynecol 2017;6:2638-40. 